\title{
DESIGN AND ANALYSIS OF FIXTURE FOR A STONE CRUSHER BODY
}

\author{
Chetan D. Borse ${ }^{1}$, Prasad V. Thete ${ }^{2}$, Ravi P. Vishwakarma ${ }^{3}$, Jainendrakumar S. Yadav ${ }^{4}$ \\ ${ }_{1,2,3,4}$ B. E. Mech.(student), Mechanical Engineering Department, Gokhale Education Society's R. H. Sapat College of \\ Engineering, Management Studies \& Research, Nasik, Maharashtra, India
}

\begin{abstract}
This paper deals with the design and analysis of the welding fixture for the body of a stone crusher. A fixture is a work-holding or support device used in the manufacturing industry. Fixtures are used to securely locate (position in a specific location or orientation) and support the work, ensuring that all parts produced using the fixture will maintain conformity and interchange ability. Locating and supporting areas must usually be large and very sturdy in order to accommodate welding operations; strong clamps are also a requirement. The toggle clamps are generally used. The body of a stone crusher consists of various plates that have to be welded to each other with a specified tolerance and weld quality. The material used in the manufacture of different parts of body of a stone crusher is Mild steel which is one of the most commonly used materials in the field of fabrication. All the welding processes are carried out by $\mathrm{CO}_{2}$ welding to ensure the quality of weld is as per the requirement. We have modeled a weld fixture by using UNIGRAPHICS NX8.0 software which is one of the software used for modeling components in most of the design based industries. While the modeling of the components the material selection is carried out simultaneously based on the design considerations related to loads, etc. Later the stress concentration and deformation on the baseplate of the weld fixture have been found by applying certain load on the baseplate, using the Finite Element Analysis (FEA) by using ANSYS software that provides best output within few seconds. Finally the stress concentration and deformation results are presented in this document.
\end{abstract}

Key Words: welding fixture, stone crusher body, toggle clamp, modeling, Finite Element Analysis.

\section{INTRODUCTION}

Bucket is the main component of stone crusher. It should be manufactured as per the accurate dimension. In industry, to manufacture the component with high accuracy, it must be properly located and hold against the work table.

\subsection{What is Fixture?}

A fixture is a device for locating, holding and supporting a workpiece during a manufacturing operation. This consists of locators, clamps, supports, and fixture body. Fixtures are essential elements of production processes as they are required in most of the automated manufacturing, inspection, and assembly operations. Fixtures must correctly locate a workpiece in a given orientation with respect to a welding torch or measuring device, or with respect to another component. Whenever any component is in space it will have 6 degrees of freedom and for correct location of that component it is required to restrict those 6 degrees of freedom. These degrees of freedom can be restricted by 3-21 location system. Such location must be invariant in the sense that the devices must clamp and secure the workpiece in that location for the particular processing operation. [1]

Fixture has direct impact upon welding quality, productivity and cost. Welding fixtures are used for holding different parts that have to be welded together. Other use of purpose of fixture is to reduce distortion that is generated during welding. It helps in reduction of production loss and also manufacturing lead time for welding, positioning and holding parts. Variety of residual stresses produced while welding is responsible for the distortion. There are many ways to control the residual stresses namely preheating, peening, post weld heat treatment, stress relief by natural ageing, vibratory stress relief. [2]

\subsection{Organization Introduction}

SINGH is one of the leading Crushing and Screening manufacturing conglomerate based in India. Since 1964, the company is engaged in designing, manufacturing and supplying World Class Quarry equipment. Right from its inception, SINGH has been a pioneer.

Reliability and Service are the bywords at SINGH. The company has a proper ratio of senior \& young technocrats. Along with the invaluable experience of the seniors and the dynamism as well as eagerness of young team members, CUSTOMER delight has been an achievable term. In most parts of the country, a crusher is synonymous with the name SINGH with more than 15000 installations worldwide.

The Company has been tremendous growth pattern for the last 4 decades. The Company has thus dedicated all its resources to delight its customers by providing them with Quality products and services. 


\subsection{Identification of Problem}

Fabrication of body is one of the problems that the manufacturer is facing during the manufacturing process of stone crusher because it takes three to four days for manufacturing.

In manufacturing of jaw stone crusher, fabrication of body is one of the most important processes. Fabrication of different plates should be very proper of the body, as the success or failure of the stone crusher is manly depending on the body.

The method they are using for fabrication of the of the body is conventional which is time consuming and some where the alignment of the different plates of body is not accurate due to which there may be a chances of failure of the body during the working condition of jaw stone crusher.

Actually the need of this project is important for crusher body because fabrication of different plates of the body having accurate alignment with heavy load of different plates is the bigger problem. The handling of different plates of body is not so easy and the effort require for fabrication is large as they are using convention method.

One of the problems, which are the sequence they are using during the fabrication of plates of the crusher body, is time consuming and large efforts require for handling of plates. Due to the weight factor the sequencing of different plates of body during the fabrication is one of the important parameter due to which more time and effort is require for handling the plates.

The aim of this project to design a fixture to locate the plates at correct place, reduce the setting time and analyze the fixture for the stone crusher body to avoid rejection and the errors in manufacturing.

\section{LITERATURE REVIEW}

Various Methods are suggested in the literature for modular fixture design. Some hybrid techniques were also being used by researchers. The review is categorized in three major classes.

\subsection{Fixture Design Methods}

Jeng and Gill (1997) formulated a fixture design problem in hierarchical design structure. Mervynet al. (2003) presented an internet-enabled fixture design system by the use of XML file format. Rios et al. (2005) and Alarcon et al. (2010) developed and presented KBE (knowledge based engineering) application for, modular fixture design. Hunter et al. (2006) presented a functional design approach in which the functional requirements and constraints are considered as an input to the fixture design process. Wang and Rong (2008) and Sun and Chen (2007) presented the case based reasoning method to provide a computer aided fixture design solution. Perremans (1996) developed an expert system for automatic fixture design [3]

\subsection{Fixture Setup and Planning}

Toumi et al. (1989) discussed the planning issues and presented the plans and requirements for automatic setup and reconfiguration of modular fixtures. $\mathrm{Wu}$ et al. (1998) developed the geometric analysis technique with modular fixture assembly to present the fundamental study of automated fixture planning. Kang and. Liu and Wang (2007) presented a hybrid approach in which machining precedence is determined by knowledge based and feature sequencing is through geometric reasoning for fixturing setup. [1]

\subsection{Fixture Verification and Analysis}

Zheng and Qian (2008) presented an efficient algorithm for optimal fixe locations to enhance localization accuracy and immobilization capability of 3-D modular fixtures for complex shapes. Wu et al. (1998) presented a geometric analysis on fixturing accuracy, clamp planning, fixturing accessibility, and clamping stability for automatic fixture planning. Song and Rong (2005) presented a methodology to evaluate the locating scheme and assist fixture designer to analyze and improve the designed scheme. Kaya (2006) presented a genetic algorithm (GA) for the optimization of locating and clamping positions for fixture layout design. [4]

\section{METHODOLOGY}

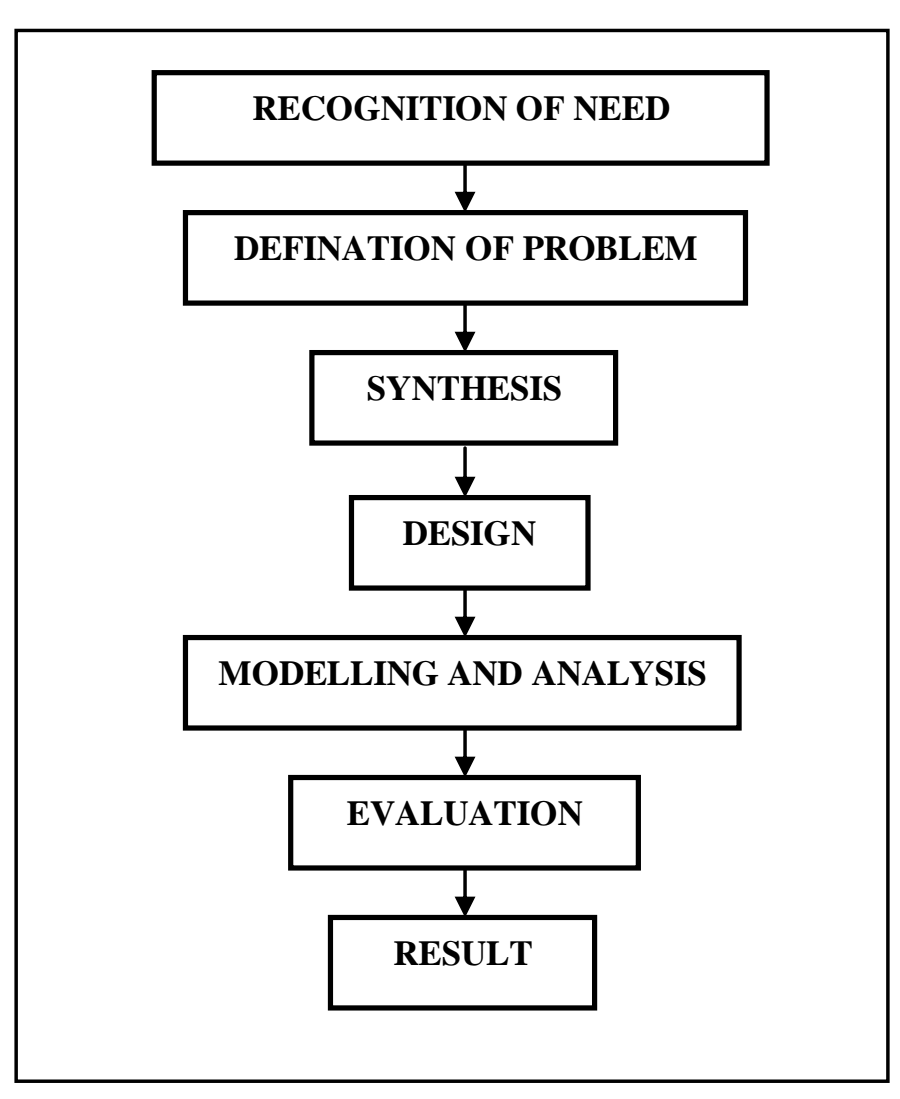

Fig-1: Stages in the design of fixture[4] 


\subsection{Synthesis}

Once the problem is defined, the next step is Synthesis. In this process we are selecting the mechanism, limit, fits, tolerances, materials, size and shape of the fixture.

\subsection{Design}

For the designing purpose we select the appropriate yield strength, ultimate tensile strength of Mild Steel, also we find out different parameter of fixture and clamping force which is required for the fixture.

\subsection{Evaluation}

To check the stresses induced in the fixture are less or greater than allowable stresses.

\subsection{Result}

By using ANSYS WORKBENCH we predict the result. That is stress in induced in the fixture and stress induced in the actual working on the machine.

\section{DESIGN AND ANALYSIS OF FIXTURE}

\subsection{Material Selection}

The material selected for fixture is MILD STEEL. [4] Steel is any alloy of iron, consisting of $0.2 \%$ to $2.1 \%$ of carbon, as a hardening agent. What is known as mildest grade of carbon steel or mild steel is typically the variety which has a comparatively low amount of carbon $(0.05 \%-0.26 \%)$.

\section{The properties of mild steel}

- $\quad$ The density of mild steel is $7861.093 \mathrm{~kg} / \mathrm{m} 3$.

- Young's modulus, a measure of its stiffness is around 210,000 MPa.

- Compared to other types of steel, this type is ideal for welding purposes, as it conducts electric current effectively without tarnishing the metal surface in any way.

- Mild steel can be machined and shaped easily due to its inherent flexibility.

\subsection{Welding Fixture}

This fixture is use to locate the various plates on their respective positions on Base plate, with the help of which following operations will going to perform on component sequentially:

- Perfect positioning

- Proper aligning

- Proper supporting

- Welding

\subsection{Calculations for the Forces}

4.3.1 Clamping Force:-It is the force to be applied in order to hold the plate in a vertical position.

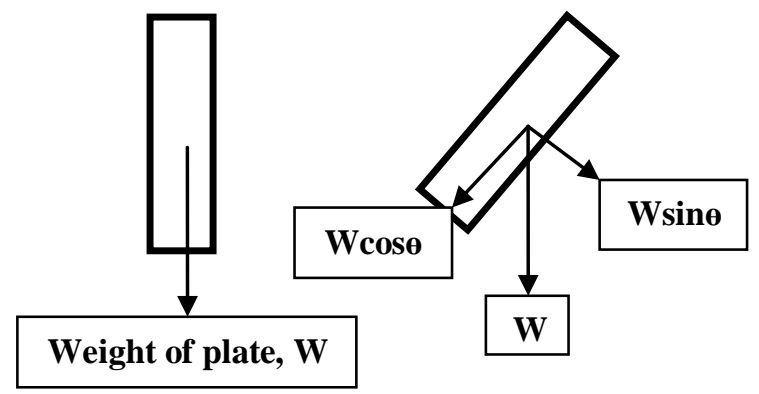

Fig -2: vertical plate.

Fig -3: inclined plate.

\section{clamping force $=W \sin \theta \times g$}

Clamping force $=200 \sin 45 \times 9.81$

(Assuming the inclination of $45^{0}$ )

Clamping force $=1387.34 \mathrm{~N}$

Considering,

\section{Clamping Force $=\underline{1500 N}$}

\subsubsection{Load on baseplate of fixture:-}

Load on baseplate=weight of body when all plates are assembled

Load $=2000 \times 9.81$

Load $=19620 \mathrm{~N}$

Considering,

\section{$\underline{\text { Load }}=\underline{20000 N}$}

\subsection{Modeling and Analysis}

4.4.1 Modeling: - By using UNIGRAPHICS 8.0 software we model the fixture

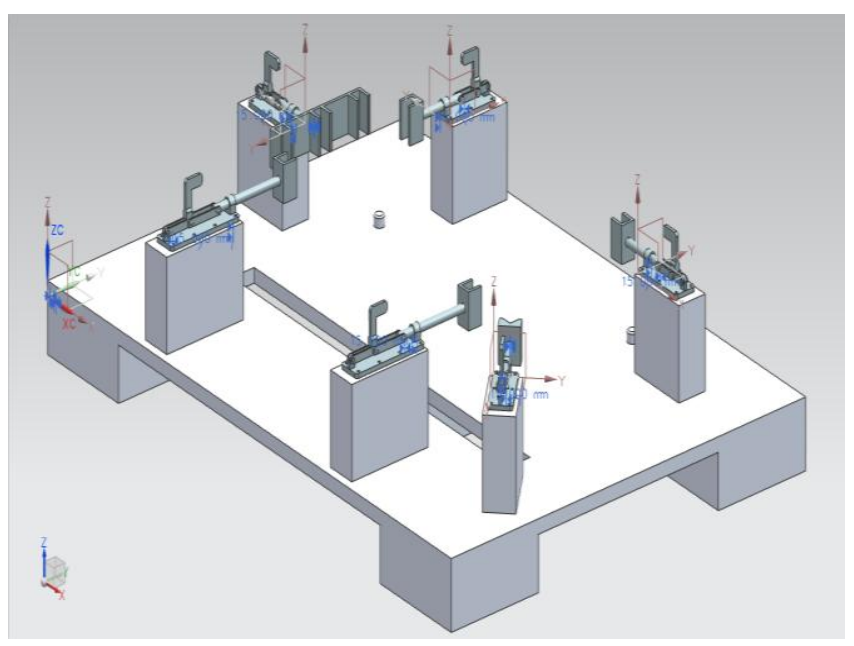


Fig -4: Modeling of fixture

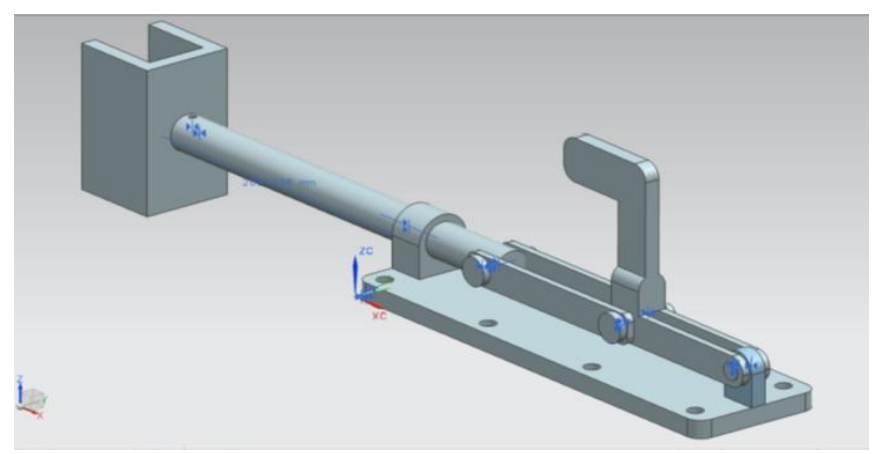

Fig -5: Modeling of toggle clamp of 200mm displacement

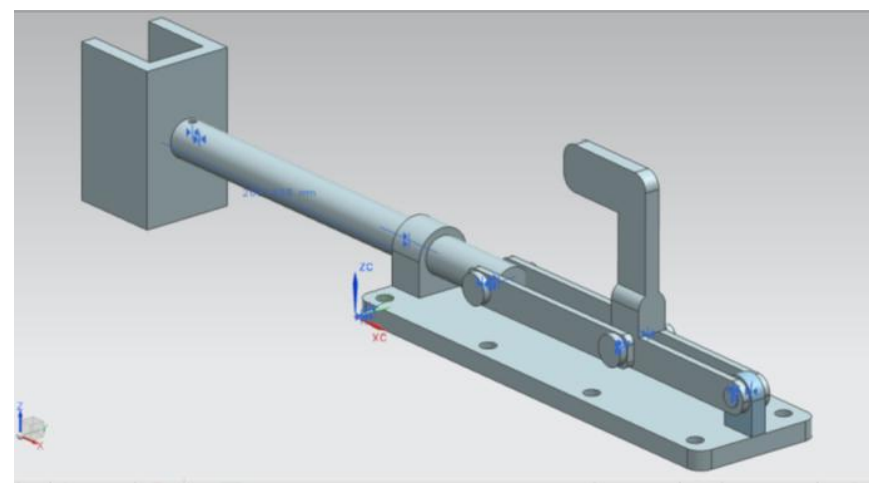

Fig -6: Modeling of toggle clamp of $100 \mathrm{~mm}$ displacement

4.4.2 Analysis: - By using ANSYS 14.5 we did the analysis of the fixture.

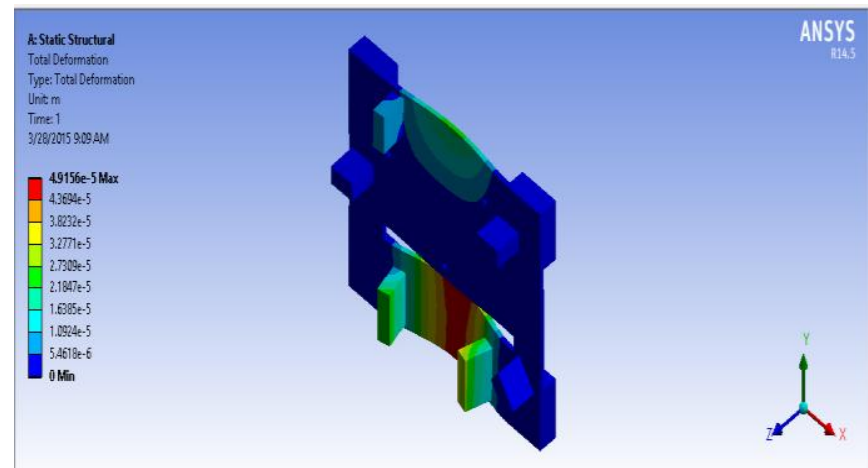

Fig -7: Total deformation of baseplate $(0-0.000049165 \mathrm{~m})$

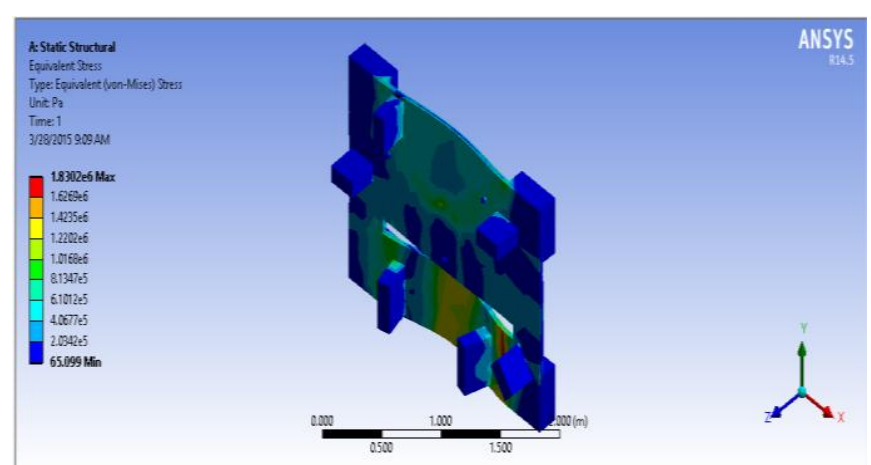

Fig -8: Equivalent (von-Mises) stress on baseplate (65.099$1.08 \mathrm{e} 6 \mathrm{~Pa})$

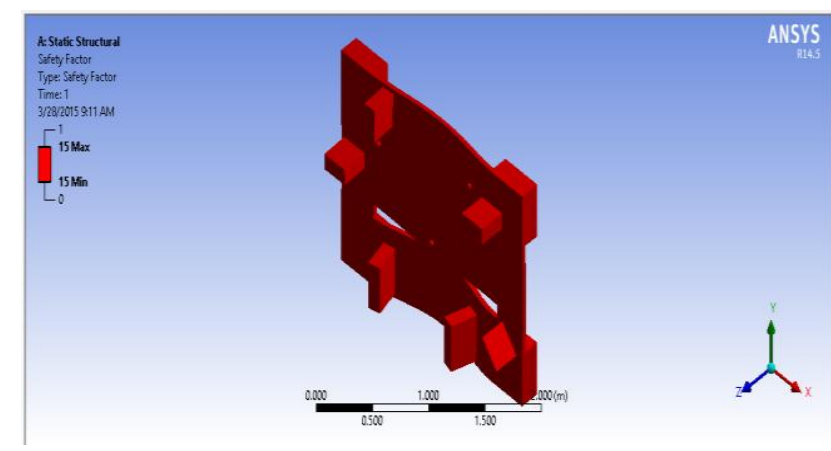

Fig -9: factor of safety of baseplate (FOS=15)

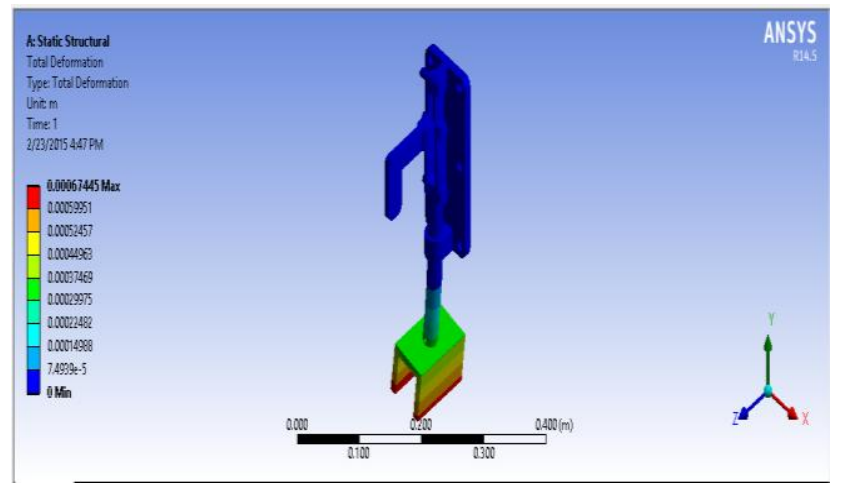

Fig -10: Total deformation of toggle clamp $(0-0.0006744 \mathrm{~m})$

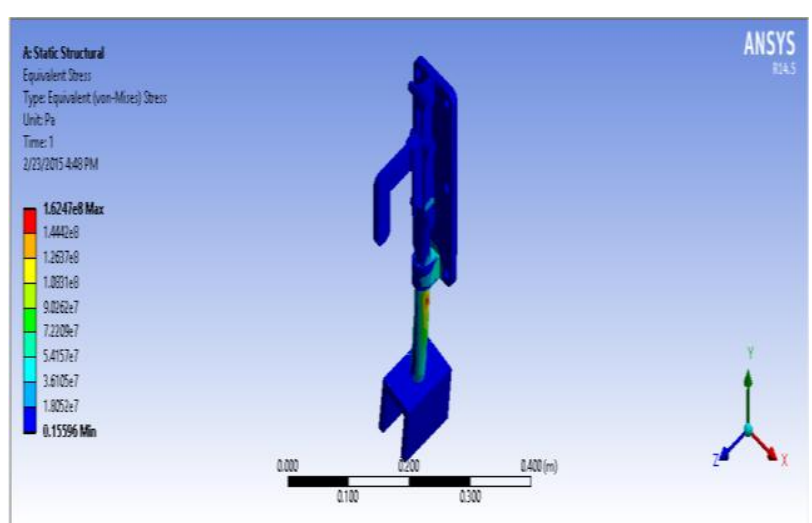

Fig -11: Equivalent (von-Mises) stress on toggle clamp $(0.15596-1.6247 \mathrm{e} 6 \mathrm{~Pa})$

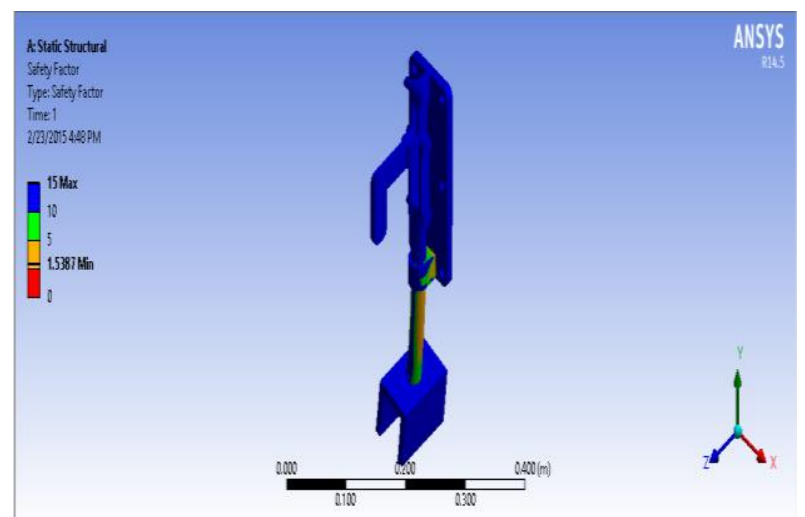


Fig -12: Factor of safety of toggle clamp $(\mathrm{FOS}=1.5-15)$

\section{TRIAL AND RESULTS}

\subsection{Trial}

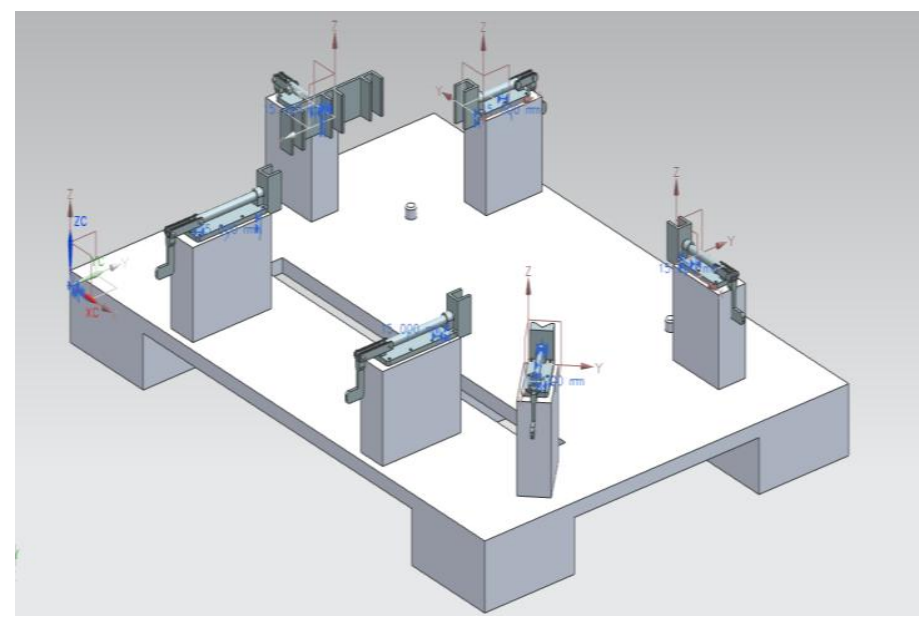

Fig -13:Fixture (All clamps are at OFF position)

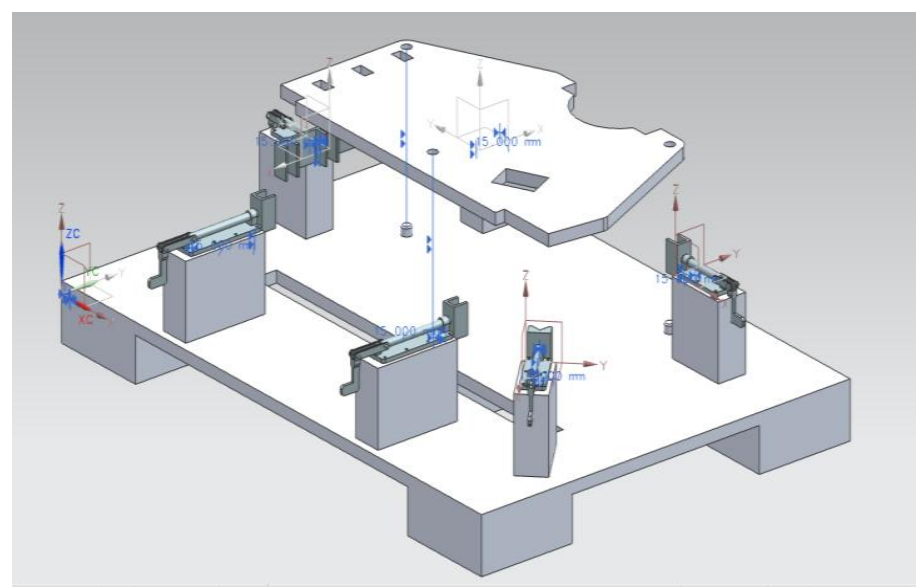

Fig -14:Step-1(Take first plate 1, align the locators with the holes in the plate)

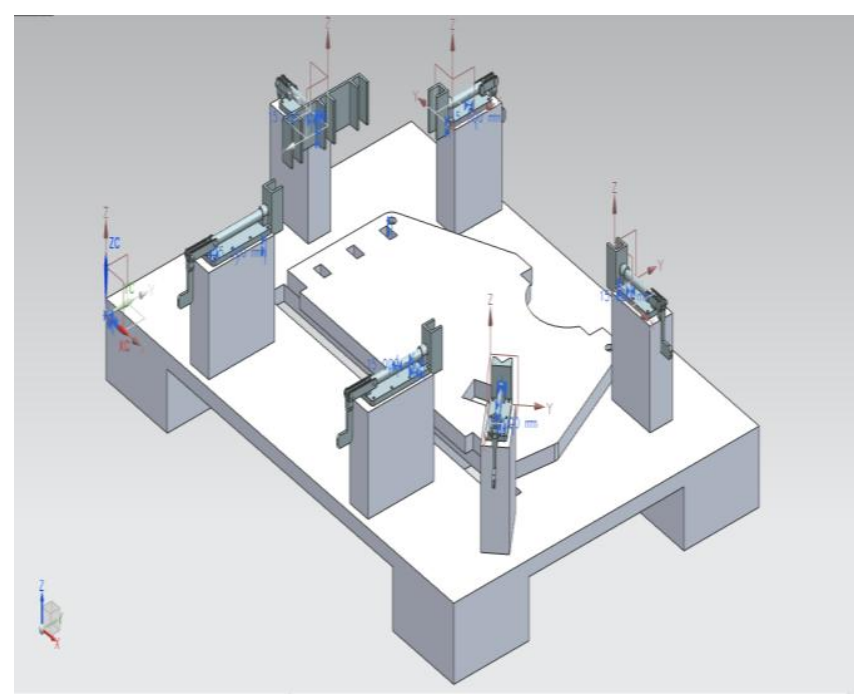

Fig -15: Stape-2(Touch the plate on the baseplate)

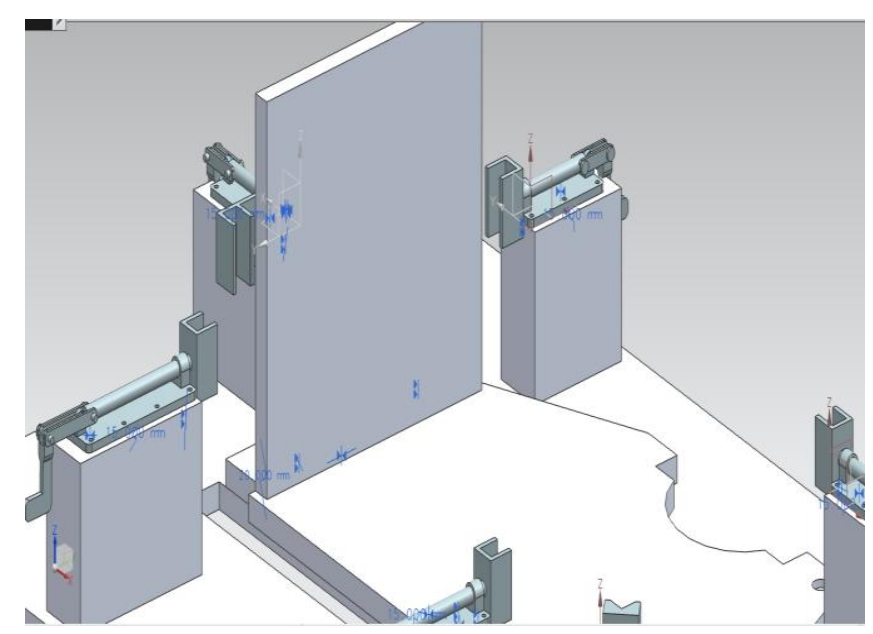

Fig -16: Step-3(Take the plate 2,place in the respective position)

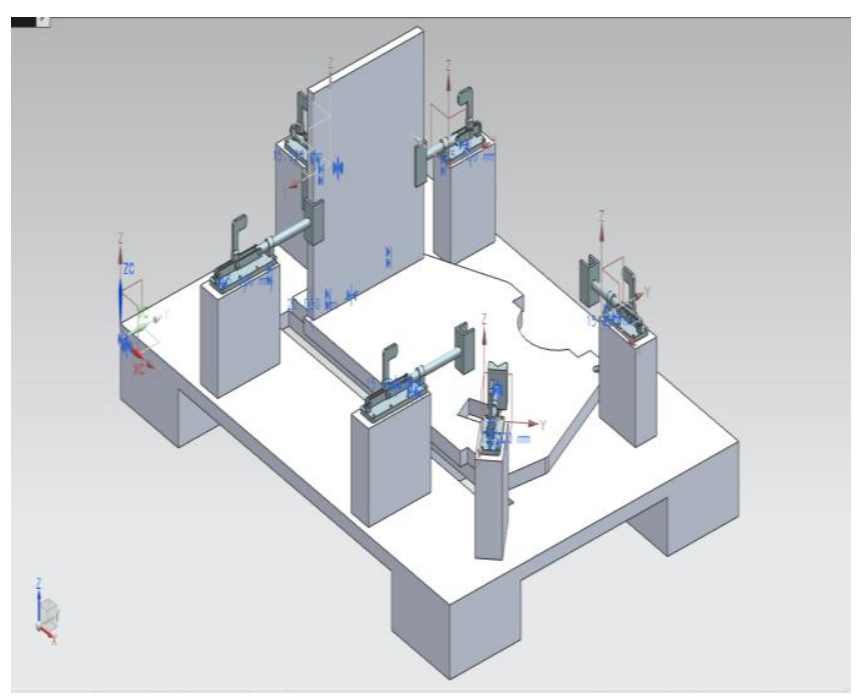

Fig -17: Step-4(Clamp the respective clamps to fix the plate in a position)

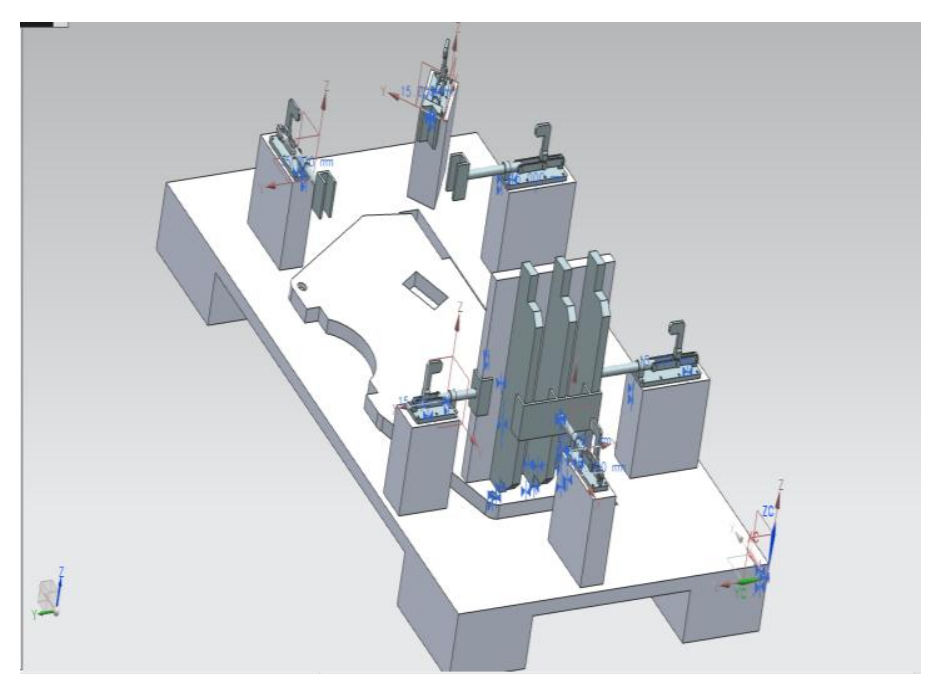


Fig -18: Step-5(Take the plate 3,place in the respective position)

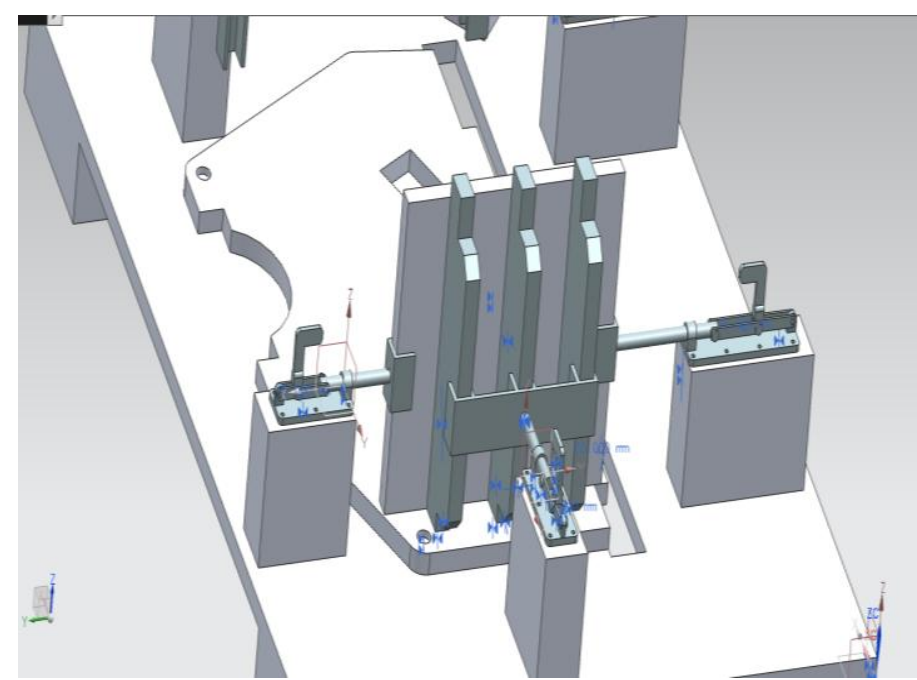

Fig -19: Step-6(Clamp the respective clamps to fix the plates in a position)

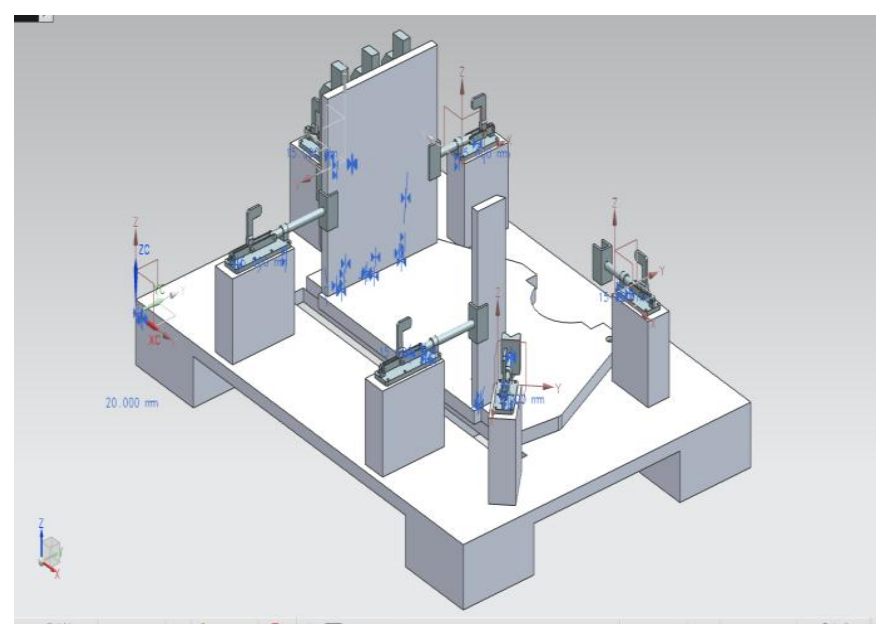

Fig -20: Step-7(Take the plate 4,place in the respective position)

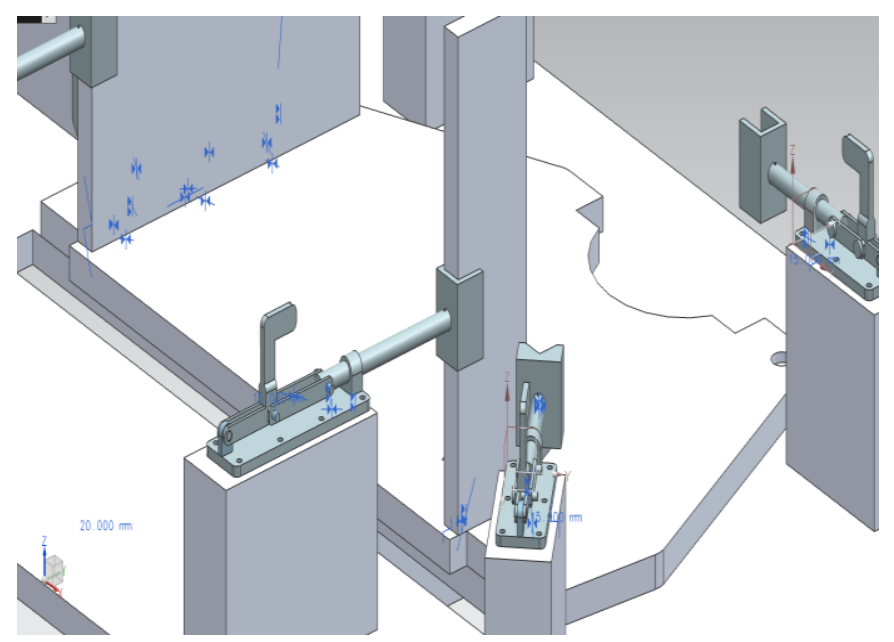

Fig -21: Step-8(Clamp the respective clamps to fix the plates in a position)

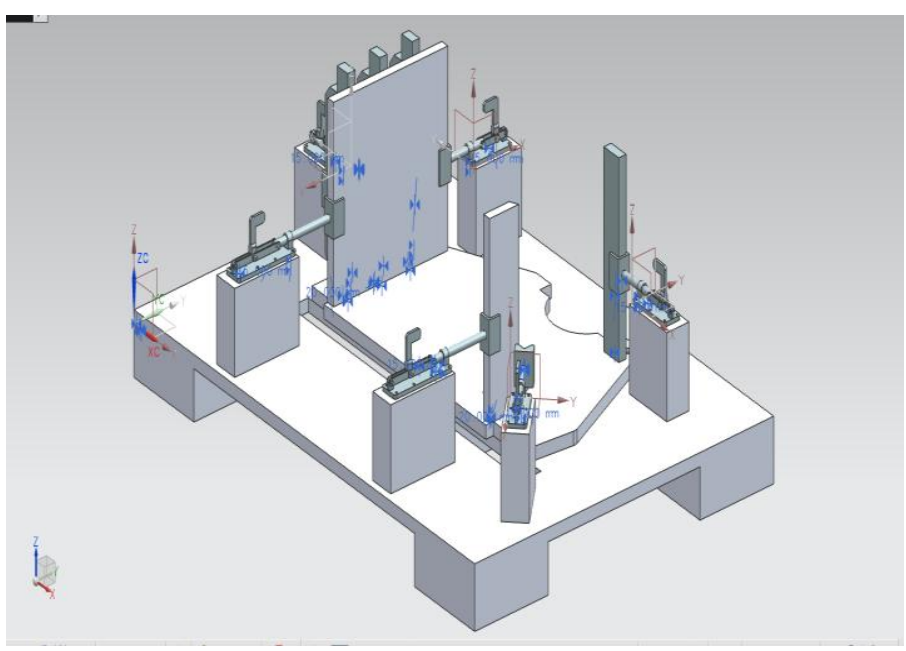

Fig -22: Step-9(Take the plate 5,place in the respective position and clamp the respective clamps to fix the plates in a position)

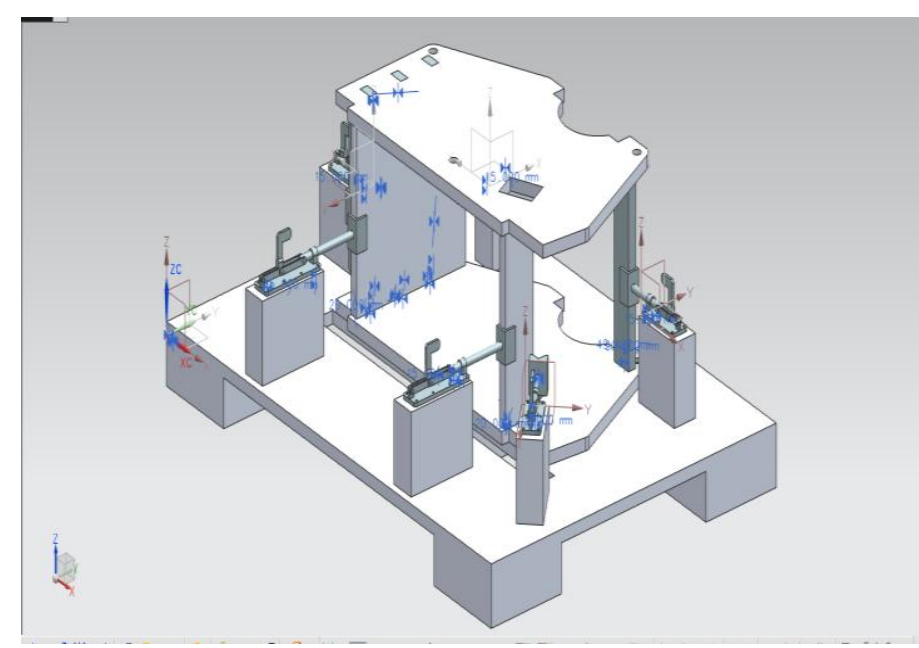

Fig -23: Step-10(Take the second plate 1,place it on the other plates, parallal to first plate 1)

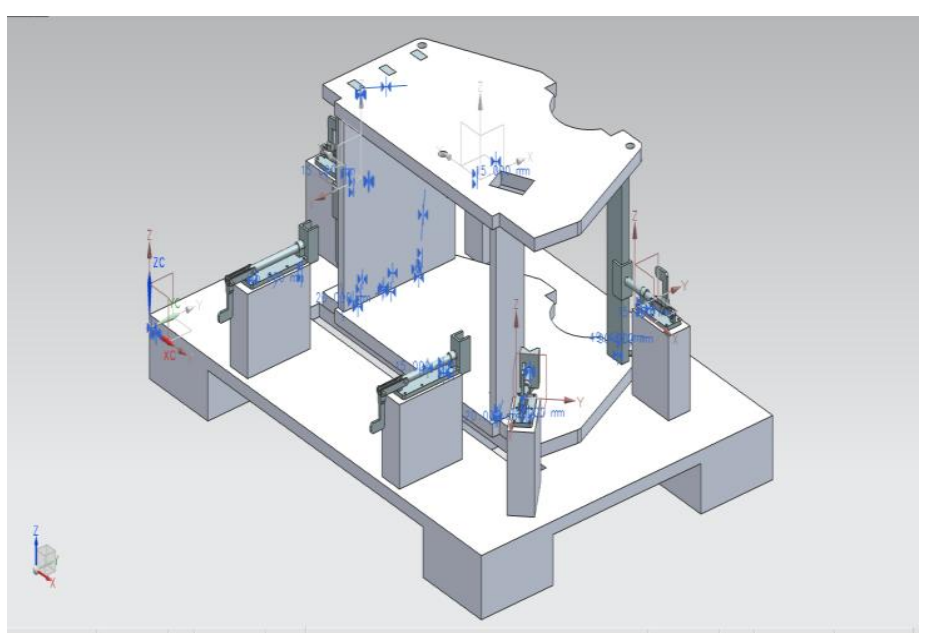


Fig -24: Step-11(Take the clamps of 200mm displacement in a OFF position)

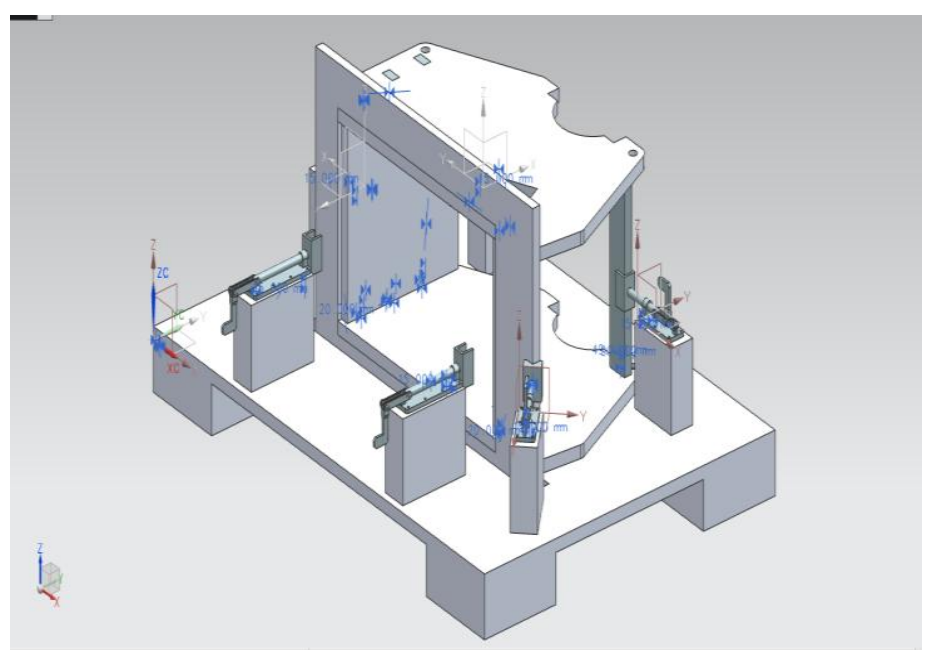

Fig -25: Step-12(Take the plate 6,place it perpendicular to the first plate 1)

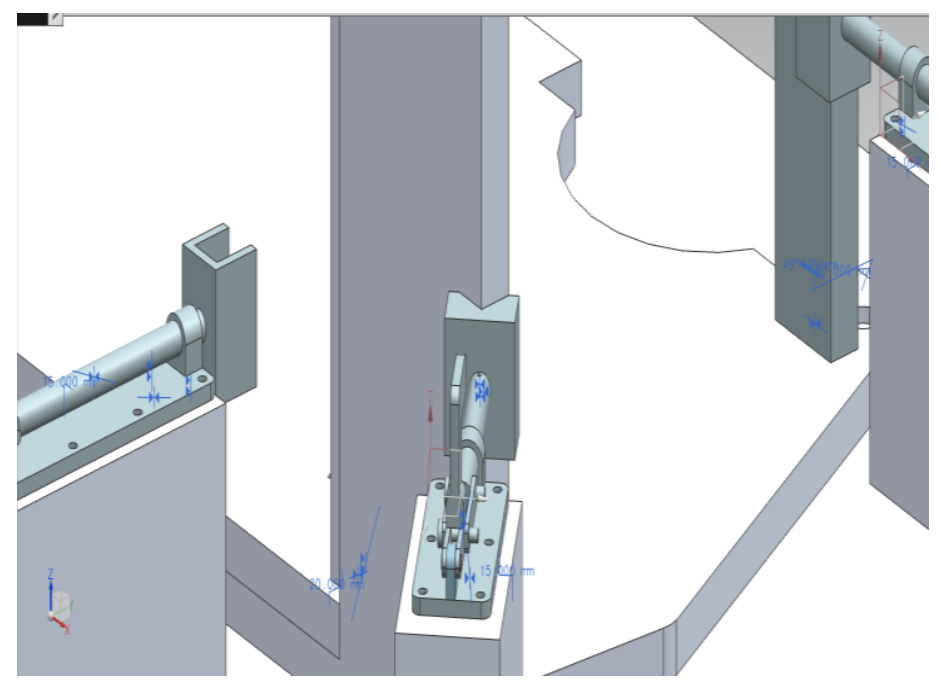

Fig -26: Step-13(clamp the respective clamps to fix the plate in a position)

\subsection{Results}

\subsubsection{Result of analysis:-}

Thus from the analysis we found that, all the stresses are within the limit (less than the allowable stresses) and the deflection is almost negligible.

Hence the design of fixture is safe.

\subsubsection{Result of trial:-}

Thus from the trial we found that the sequence of assembly is suitable and less efforts are required than the previous sequence.

\section{CONCLUSIONS AND FUTURE SCOPE}

\section{Conclusion}

In this paper, the design and analysis of welding fixture for stone crusher body is performed successfully and in this process of designing,

The modeling of each part of the head end sub assembly and the welding fixture is carried out better visual realization of the components, this modeling of the parts is modeled package UNIGRAPHICS NX 8.0. This method of modeling the parts evolves the better analysis towards the tolerances on the fixture design. The analysis is done by ANSYS 14.0 WORKBENCH.

The sequence of the welding operations and is found to be one of the optimum sequence in this crusher body welding. The each weld setups are stated and are briefed using the figures at each step of welding using the welding fixture.

\section{Future Scope}

In these Fixtures clamping are done by manually, but in future by using automated clamping such as pneumatic or hydraulic clamping we can achieve higher production rate.

By making the fixture adjustable and by increasing the size of the fixture, bodies of various sizes can be welded on the same fixture, which is resulting in increase of the production rate.

\section{ACKNOWLEDGEMENT}

First of all I would like to thanks my parent for it would have not be possible the complete the project without their guidance and moral support.

And we were lucky to be blessed with an opportunity of make a project under a guidance of Prof. K. V. Chandratre (HOD) and with the help of all instructors.

I feel privilege to acknowledge with deep sense of gratitude of my guide Prof. B. V. Varade for his valuable suggestion and guidance throughout my course of studies.

I also thank to our project co-ordinator Prof. D. S. Chaudhari and Prof. Sagar Deshpande for their guidance in design and analysis.

I also expressed to Mr. Gurmeet Singh Birdi (Co-owner SINGH ENGINEERING WORKS) for their kind CoOperation.

The project would have not been completed if we would have not mated the Sponsorships of SINGH ENGINEERING WORKS, MIDC Area, Satpur, Plot No. C-2, Industrial Estate, Nasik-422007, Maharashtra, India 


\section{REFERENCES}

[1] "JIGS AND FIXTURE DESIGN", Edward G. Hoffman; Thomson Publications; Fifth Edition.

[2]. Hui Wang, Yiming (Kevin) Rong," Case based reasoning method for computer aided welding xture design", Polytechnic Institute, Worcester: May,2005.

[3]. Rong, Y and Zhu, Y, 1999; "Computer-Aided Fixture Design", Marcel Dekker Inc. NY; 1999.

[4]. H. Song and Y. Rong; Locating completeness evaluation and revision in fixture plan, Robotics and Computer-Integrated Manufacturing 21 (2005) 368-378

\section{BIOGRAPHIES}

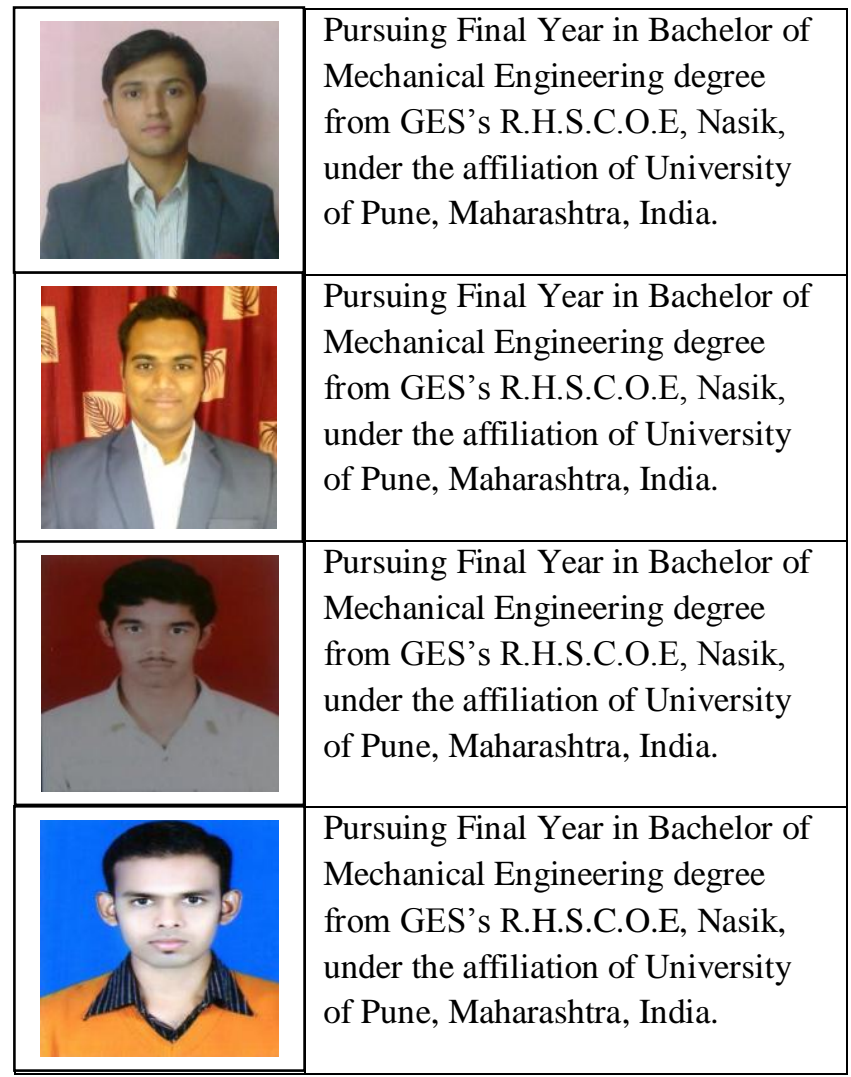

